Published in final edited form as:

Cell Mol Life Sci. 2011 June ; 68(11): 1871-1881. doi:10.1007/s00018-011-0663-0.

\title{
Matrix control of scarring
}

\author{
Cecelia C. Yates, \\ Department of Pathology, University of Pittsburgh, 3550 Terrace St, Scaife Hall, S-713, \\ Pittsburgh, PA 15261, USA
}

Richard Bodnar, and

Department of Pathology, University of Pittsburgh, 3550 Terrace St, Scaife Hall, S-713, Pittsburgh, PA 15261, USA. Pittsburgh VAMC, Pittsburgh, PA 15261, USA

\author{
Alan Wells \\ Department of Pathology, University of Pittsburgh, 3550 Terrace St, Scaife Hall, S-713, \\ Pittsburgh, PA 15261, USA. Pittsburgh VAMC, Pittsburgh, PA 15261, USA
}

Alan Wells: wellsa@upmc.edu

\begin{abstract}
Repair of wounds usually results in restoration of organ function, even if suboptimal. However, in a minority of situations, the healing process leads to significant scarring that hampers homeostasis and leaves the tissue compromised. This scar is characterized by an excess of matrix deposition that remains poorly organized and weakened. While we know much of the early stages of the repair process, the transition to wound resolution that limits scar formation is poorly understood. This is particularly true of the inducers of scar formation. Here, we present a hypothesis that it is the matrix itself that is a primary driver of scar, rather than being simply the result of other cellular dysregulations.
\end{abstract}

\section{Keywords}

Fibrosis; ECM; CXCR3; Tenascin C; Fibronectin

\section{Introduction}

The wound site constitutes the most active and diverse organismal process outside of embryogenesis. Immediately upon injury a series of events is initiated that trigger the proliferation, migration, and phenotypic plasticity of cells of a multitude of origins, with the ultimate goal of restoring tissue integrity and homeostasis [1-3]. The network of effectors includes not just the resident parenchymal stromal (fibroblasts) and epithelial (keratinocytes for skin) cells but also endothelial cells, cells of the hematopoietic lineage, neurons, and even stem cells [4-6]. These cells function in a highly communicative and coordinated manner to recreate the formed elements and supporting matrices of the organ [7].

The end of this process is generally one of two outcomes. It needs to be noted that chronic wounds and continuing ulceration are less common pathologic conditions not considered here $[8,9]$. One common outcome is a successful response in which the process of repair occurs and shuts down under precise sequencing and timing; this is known as regeneration. The other result is an uncontrolled event that in many cases results in a disorganized matrix

(C) Springer Basel AG 2011

Correspondence to: Alan Wells, wellsa@upmc.edu. 
that is characterized as fibrosis [10-12]. However, these are not fully exclusive outcomes as there are often elements of both in the healed wound. For most adult skin injuries, the wound results in a disorganized extracellular matrix (ECM) that forms a scar, though the degree to which this occurs is variable [7,13-16]. Most often, the scarring is limited in scope and duration, with the initial scar being re-organized into more physiologically functional tissue over the ensuing months [17]. In many tissues, and especially during the fetal period, the result of the healing is towards regeneration with the resultant tissue nearly indistinguishable from uninjured tissue [4, 18-21].

The control of healing, and the direction towards scarring or regeneration, is the subject of intense investigation. What is known is that the tissues respond to both endogenous and exogenous stimuli. Furthermore, the ECM of the wound is both a major structural element and an active signaling element. While the structure of matrix and the components therein largely define scar, these are not inert elements; not only does the matrix contain predeposited factors and adhesion sites but also cryptic signaling elements (matrikines and matricryptins) [22-24]. This duality of function leads us to propose that the nature of the matrix and its maturation or evolution during wound resolution plays a major role in determining whether the healing process results in a fibrotic outcome or a regenerative one.

More specifically, questions still remain as to what triggers the re-emergence of a chronic inflammatory situation in a sterile wound environment late in remodeling that subsequently results in fibrosis. Are there chemotactic extracellular components or fragments that initiate the reappearance of inflammation during late matrix remodeling? This review provides an overview of key matrix players involved in orchestrating remodeling of the matrix and cellmatrix interactions that governs the outcome. Soluble factors and immunological aspects that contribute to scarring have received extensive coverage recently; rather, we provide a distinct but complementary perspective on another set of key initiators of scarring, the matrix-derived signals inherent in an immature matrix, and the role, if any, they play in eliciting non-resolving inflammation seen in wound maturation.

\section{Diverse outcomes of the healing process}

All multicellular organisms must respond to injury. However, the outcome of such responses can either generate fibrotic tissue, simply close a gap in the organ without replacement, or proceed to regenerate the missed tissue in fully functional form [25, 26]. While the differences are often striking as one proceeds along the phylogenetic tree, even in humans the outcomes diverge [27]. For example, fetal healing is typically characterized as a process that is rapid and results in regeneration of physiological tissue in a process referred to as scarless healing [27-30]. In contrast, a much slower process that results in scarring is seen in adult healing [31, 32]. A number of underlying diseases or genetic predispositions accentuate dysregulated healing or even activate the scarring process in the absence of insult. This leads to pathological conditions as seen in a variety of fibrotic diseases such as single organ fibrosis of the lung, heart, liver or more widely distributed diseases like scleroderma or connective tissue diseases [33-35]. Even though fibrosis may not be the primary triggering event in these diseases, it is the main element of the morbidity and mortality [36]. These diseases are thus characterized by ongoing fibrotic generation in the absence of external injury or insult. Understanding the fibrotic aspect and the mechanism of such will serve as a key in developing therapeutic approaches.

For all organs, the normal adult response to injury occurs in four, overlapping but interrelated, time-dependent phases: hemostasis, inflammation, tissue formation/regeneration, and tissue remodeling/resolution $[1,37]$. All these events require extensive communication between diverse cell types and input from the prior phase [38-40]. Hemostasis initiates with 
the platelet plug and other coagulation events, such as serum protein cross-linking and vascular constriction [7, 41, 42]. The aim is to prevent exsanguination and maintain adequate volume and pressure for uninjured organs and tissue. In addition, the serum proteins and platelet lysate provide a provisional matrix to support the wave of cells that follow. Inflammation is concomitant with this initial phase as numerous elements of the innate immunity are trapped within the initial platelet plug [41]. In addition to further infiltration of the hemostatic plug secondary to chemoattractants released by platelets, these cells, mainly neutrophils and macrophages, provide for anti-microbial defense and remove dead cells and tissue $[42,43]$. Importantly for our thesis, these cells produce ECMmodifying enzymes and, the macrophages in particular, matrix components that, together with the deposited fibrin, influence the entire subsequent reparative process. It is these deposits that hold damaged tissue together and provide a provisional matrix for the initial recruitment of inflammatory cells and later the migration of other resident cells including vessels and nerves [1, 44-47] (Fig. 1).

Neutrophils are the most abundant cells in the early inflammatory stages of healing. Neutrophils have diverse roles being part of innate immunity and signaling to other immune and adherent cells. As a critical phagocyte, neutrophils destroy and remove bacteria, foreign particles and damaged tissue. As neutrophils die, macrophages predominate, accumulating at the wound site following recruitment from circulation and from the resident population [48]. The two initial waves of macrophages, over the first few days post-wounding, involve mainly a M1 phenotype that if not present leads to impaired healing with limited wound maturation [48]. These macrophages act in unison with neutrophils to phagocytose debris and invading pathogenic microorganisms. A second role for these cells is as a source of chemoattractants and growth factors such as TGF- $a$, HB-EGF, PDGF, and TGF- $\beta$ that act on the formed elements of the wound to promote immigration, proliferation and survival of these cells [44, 49-51]. These factors are also angiogenic [52]. The invading cells, along with the macrophages, change the matrix from a loose fibrin lattice into the provisional matrix rich in fibronectin, hyaluronic acid, tenascin, and collagen and laminin types representative of an immature matrix [48, 53-55].

This invasion by formed elements—-stromal cells, epithelial cells, vasculature, and nervesmarks the tissue formation/regeneration phase. This is characterized by the presence of relatively undifferentiated cells that are both proliferative and migratory, but do not fully function as their mature counterparts in the unwounded tissue. For the epithelial cells, this may be considered a transient epithelial mesenchymal transition (EMT), in which the mesenchymal keratinocytes cells present a less mature phenotype that not only provides for enhanced migration but also produces matrix components [56]. Of note, the matrix at this phase resembles that during development and even tumor invasion. It has been shown that such a matrix is not just a product of an active unformed tissue but a stimulator of such. Tumor-associated matrix can drive a transient EMT in normal epithelial cells $[7,57,58]$. The high levels of tenascin-C, fibronectin, and entactin coupled with very low levels of the small leucine-rich proteoglycans (SLRP), such as decorin and lumican, trigger cell proliferation and migration [22, 23, 59-61]. At the same time, the cells are maintained in a less differentiated state, approaching EMT for the epithelial elements.

Similar to development but in contrast to tumor progression, this metaplastic stage is shortlived as the wound enters the remodeling/resolving phase [37, 57]. During this phase, the excessive cellularity of the regenerative phase is reversed with active apoptosis of stromal and epithelial cells, and dissolution of immature vessels. The ongoing cell proliferation is suppressed, with the balance shifting dramatically towards loss of cells. In skin wound healing, over $90 \%$ of the vessels and other formed elements may be lost during this period. This shift in cell concentration is an active process, in which a maturing matrix plays an 
active role [23, 62]. The remodeling phase involves the rapid degradation of components of the immature matrix and equally rapid synthesis of mature connective tissue proteins. The total amount of collagen increases as the stimulation of collagen I synthesis exceeds that of collagen III and other forms [62, 63]. Furthermore, the markers of matrix immaturity, fibronectin and tenascin-C, disappear and the SLRP content, such as decorin, lumican, and biglycan, increases dramatically [22, 59]. High concentrations of collagen I fibrils, particularly if crosslinked, are highly adhesive, a property that limits cell migration, while the SLRP molecules downregulate the signaling from a variety of growth factor receptors $[22,63]$. Not only does this matrix reverse the stimulatory environment of the preceeding phase but these proteins couple with soluble chemokines to drive matrix contraction by the stromal cells (fibroblasts and myofibroblasts) to form a scar [64, 65].

The healing process in adults concludes with the resolution of the scar over the ensuing months. Collagen levels returns to normal tissue levels, as the tissue approaches, but does not reach, pre-injury homeostasis.

Unfortunately, this process does not always go as planned. In many instances, the scar will continue to remodel, grow, and expand resulting in clinically dysfunctional and debilitating scar. Here, we present evidence to suggest that, when matrix maturation is disrupted, chronic inflammation ensues even in the absence of continuing external stimuli or insults.

\section{Extracellular matrix alterations during healing}

Healing and fibrosis result from a difference in the balance of the biosynthetic and degradative pathways of ECM restructuring. The precise molecular mechanisms that underlie the ECM-mediated regulation and cell/matrix interaction of the complex processes of wound healing and fibrosis is not fully understood; still, a coherent view of the interplay between the cells and matrix is emerging. Specifically, a number of ECM constituents that directs dermal cells to further alter ECM synthesis and turnover have been identified. Here, we discuss these in terms of the continuous remodeling that characterizes the scarring process.

The ECM is assembled from components synthesized and deposited outside the cell surface that provide structural and functional integrity to connective tissues and organs [66]. The synthesis and deposition of ECM largely occur in response to growth factors, cytokines, chemokines and mechanical signals mediated via cell surface receptors [22, 67]. These signals influence various processes at the wound site including stimulation of keratinocytes and fibroblast proliferation and migration, influx and activation of inflammatory cells, and the synthesis and breakdown of ECM proteins [68] (Table 1).

\section{Cell-matrix interaction}

Collagen is the most abundant component of ECM and forms its fibrous backbone.

Collagens control tissue architecture, tensile strength, cell-matrix, and matrix-matrix interaction. At least 18 different types of collagen have been associated with skin injury and scarring; fibrillar collagens such as type I and III are major constituents of scar tissue.

Collagen type I forms a relatively rigid, linear fibrillar network [63, 69]. During the healing process increased collagen deposition is contributed by both resident dermal fibroblasts and at the wound edge by immigrating cells including keratinocytes [70, 71]. The level of collagens during healing is regulated by synthesis and degradation. Interestingly, the fibroblast is the main cell type that both synthesizes and degrades ECM components, with this being orchestrated by growth factors and chemokines in endocrine, paracrine, and autocrine fashions [72-74]. It is these mediators that stimulate the rates of collagen synthesis and degradation during healing. Of interest for scarring, collagen fragments liberated during 
degradation are chemotactic for inflammatory cells. When this balanced synthesis/ degradation process tips towards excessive turnover, such elements recruit cells that result in excessive scarring.

Fibronectin is an adhesive protein component of ECM involved in cell attachment and chemokinesis (Table 1). This 540-kDa glycoprotein is a homodimer. Fibronectin exists as a soluble dimer in the blood plasma as well as a fixed component of fibrous ECM and basement membrane $[75,76]$. Immediately upon injury, a provisional ECM, consisting predominantly of fibrin and plasma fibronectin, is generated from these plasma proteins. Deposition of this matrix temporarily fills the wound bed and prevents excessive blood loss by acting as a haemostatic plug. By binding to distinct domains of plasma-derived fibronectin via $a 5 \beta 1, a 4 \beta 1$ and $a v \beta 3$ integrins, syndecan- 4 and CD 44 , fibroblasts are able to migrate into the provisional matrix $[69,76]$. These cells then produce more fibronectin to reinforce the granulation tissue scaffold for the deposition of collagen [77]. The consequential scar tissue is remodeled, and, in time, the collagen becomes cross-linked while never truly restoring the cellularity, vascularity and tensile strength of the original tissue. The rate-limiting step is the delicate balance of granulation tissue production: too little results in chronic non-healing wounds while too much results in slowly healed resolved wound or deposition of scar tissue, which is the marker of fibrotic disease. Thus, the immigration of fibroblasts into fibrin-fibronectin matrices is tightly regulated.

Tenascin-C plays a unique role in tissue repair and regeneration. This molecule is by and large restricted to sites of organogenesis, tissue repair/regeneration, and tumor invasion. During repair, tenascin- $\mathrm{C}$ is transiently expressed [55]. In unwounded and healed tissue, tenascin- $\mathrm{C}$ is largely absent. Tenascin- $\mathrm{C}$ presents as a dimer of homo-trimers, giving it the alternate name of hexabrachion (Table 1). Tenascin-C has multiple repeats of fibronectinlike domains and EGF-like repeats, with the former binding integrins and the latter serving to bind to matrix components and signal through the EGF receptor [78-80]. Thus, tenascin$\mathrm{C}$ has both adhesive and anti-adhesive interactions. Interestingly, tenascin $\mathrm{C}$ presents cryptic ligands (or so-called matrikines), molecules that result in partial proteolysis of ECM macromolecules and regulate cellular activity, activate EGF receptors to promote fibroblast and endothelial cell migration, and maintain fibroblasts in a dedifferentiated, noncontractile state. To a certain extent, the cellular influx and thereby replacement of tissue appears to be under the influence of tenascin- $\mathrm{C}$, thus influencing the functionality of the tissue directly as a major matrix component during repair and indirectly via the cellularity of the regenerative and resolving dermis. The net result is that tenascin-C acts as a chemokinetic agent that promotes cell distribution throughout the wound bed, affecting all the adherent cells. In addition, this complex molecule promotes survival of cells. During inflammation, upregulation of tenascin- $\mathrm{C}$ is chemokinetic and anti-apoptotic, leading to accumulation of excess cells and, secondarily, matrix components [81]. In addition, it may be possible that tenascin-C prevents the maturation and differentiation of stromal and epithelial cells, thus leading to further accumulation of a bioactive provisional matrix, in a feed-forward reaction. On the other hand, downregulation of tenascin-C production by stromal and epidermal cells, and clearance of deposited tenascin-C, both of which occur during the latter phase of healing, heralds the transition from hypercellular regenerative phase to a paucicellular resolving and mature phase. It is quite likely that loss of tenascin-C from the matrix allows, in part, the apoptotic removal of cells. Thus, persistence of tenascin-C may promote prolonged fibrosis. Additionally, downregulation or removal of tenascin-C expression and clearance from the wound would then allow contraction to proceed, indicating that tenascin$\mathrm{C}$ exerts temporal control over cell behavior during wound healing [22, 23, 82].

Entactin (or nidogen) is a 141-kDa multidomain glycoprotein serves as a ubiquitous component of basement membranes. This molecule interacts both with other components of 
the ECM and cells. This molecule functions in a quasi-autocrine manner in that stromal cells are the source and target of entactin [83]. Due to entactin's strong affinity for laminin and collagen IV, it holds an important role in skin remodeling. Interestingly, entactin is highly susceptible to proteolytic cleavage with removal of entactin initiating basement membrane disintegration. Thus, it is suggested that entactin facilitates the fast remodeling of different matrices and could serve as an early target in tissue damage and control the scar formation outcome [84] (Table 1).

In contrast to the above structural and pro-inflammatory molecules, the unwounded or healed matrix contains numerous 'suppressive' molecules. Decorin is a small ECM chondroitin/dermatan sulfate proteoglycan that belongs to a growing family of structurally related but genetically and functionally distinct ECM proteoglycans (SLRPs). The SLRP gene family has been subdivided into three classes, I-III, with decorin and biglycan belonging to class I [85]. The structural features of decorin provide sites for multiple interactions, either as a dimer or a monomer, with other molecules present in the ECM. Decorin is the most abundant proteoglycan in normal dermis. It regulates the formation and degradation of collagen fibrils in a manner that in most situations promote fibrillogenesis $[85,86]$. In its absence, the structure and organization of collagen fibrils turn into distorted whorls and nodules [86]. There is a close association between decorin and matrix synthesis and organization via TGF- $\beta$ signaling. Decorin, which downregulates the activity of TGF- $\beta$, increases in concentration following tissue injury. However, in scarring, decorin is a component in the ECM that is significantly decreased thus allowing the profibrotic TGF- $\beta$ to act. Interactions of decorin with other ECM proteins such as collagen types, fibronectin, thrombospondin, tenascin-C, and indicate that decorin is involved in ECM assembly. Decorin has been shown to be able to modulate ECM composition and turnover, with key roles in cell adhesion, migration, and proliferation [87]. The effect of decorin on these cellular processes is mediated not only by the ability of decorin to bind to other ECM molecules but also to its ability to bind to and to regulate the activity of a number of growth factors and chemokines (Table 1). Thus, decorin can be a key player in influencing repair and remodeling of damaged tissues and scar formation, normally limiting scarring both by ameliorating factors that induce fibrosis and fibroplasia and by organizing the ECM [88]. Its downregulation in immature matrix, and chronic inflammation thus opens the avenue for continued matrix production.

Extracellular matrix-chemokine interactions are fundamental to all phases of wound healing and are not limited to dermal maturation. Cell that are regulated by chemokines to synthesize ECM proteins must meet the production demands of the wound environment by exhibiting sustained activity needed to accomplish optimal healing. However, it seems that, when these demands are not met, healing is delayed, and healing events fail to proceed in the cell-matrix regulated manner. Chronic wounds result and they are often characterized by an excessive inflammatory character.

\section{Molecular controls of wound resolution}

The transition from the regenerative active phase to the resolved quiescent phase is critical. This is a poorly understood phenotypic change, with studies challenged by the diversity of cell and matrix types involved, the heterogeneity of the transition, and the wide time window of such a change, which occurs incrementally rather than continuously. A number of molecules have been suggested as triggering this maturation in one of the cell types. Angiopioetin-2 causes endothelial cell apoptosis and distintegration of vessels. Cell-cell adhesion molecules, E-cadherin and desmoplakins, have been implicated in epithelial and epidermal differentiation after the EMT of wound repair. 
The ELR-negative CXC chemokines are particularly attractive master regulators that bind to the ubiquitous CXCR3 receptor [89]. This signaling network was first deciphered as a chemoattractant system for immune cells of hematopoietic origin [90]. Subsequently, this receptor was found on formed elements, and some of the ligands, notably CXCL10/IP-10 and CXCL11/IP-9, were discovered to be produced by such cells, allowing for para- and autocrine signaling during wound repair [91, 92]. While one member, CXCL4/PF4, is present at the earliest stage of wounding, being a major constituent of platelet alpha granules, CXCL10 and CXCL11 are produced late in the regenerative and into the resolving phases of wound repair $[92,93]$. Our recent studies have found that, by triggering these receptors on fibroblasts and endothelial cells, their ligands affect vascular regression and endothelial and stromal cell apoptosis [92, 94, 95]. At the same time, via PKA-mediated inhibition of $\mathrm{m}$-calpain activation, signaling through CXCR3B prevents immigration and locomotion of these same cells [92, 93, 95, 96] (Fig. 2). Interestingly, the same signaling network in keratinocytes leads to increased locomotion [91, 92]. Thus, this signaling axis actuates a comprehensive set of behaviors that would transition a wound from the regenerative phase to the final phase of wound resolution.

It should be noted that this regenerative phase, in which the missing tissue is replaced by new matrix and cells, usually does not lead to true tissue regeneration in the adult skin; rather, it is a phase of the wound healing process in which tissue (ECM and cells) is generated de novo, though imperfectly. It is the nature and timing of this phase, impacted by inflammation and other external stressors, that dictate much of the outcome of the wound healing.

Recently, we reported a situation in which a wound bed continues to undergo the regenerative phase processes and even experiences an inflammatory recrudescence over an extended time period, leading to hypertrophic scarring. This happens in the absence of the stop signal, CXCR3. Full thickness wounds in mice lacking CXCR3 close, but over extended periods they continue to be active, resulting in hypertrophic and hypercellular wounds $[93,97]$. The continued regenerative processes of these wounds undergo an inflammatory renaissance over an extended time period. This sterile inflammatory response serves to further the events of the active turning over of the immature wound bed [98].

These data further support the notion that regulation of cell involvement by recruitment, replication and matrix synthesis, and degradation, all which affect the outcome of injured tissue, are controlled by mediators from both inflammatory and resident cells. Which further raises the question, can this fibrotic environment be generated by a combination of a dysfunctional mechanical environment and inflammatory mediators?

\section{Failure to transition to resolution}

It is clear that inflammation can influence the wound repair process when the inflammation continues after the initial task of preventing conventional infection. This is particularly true when inflammation occurs late in the regenerative or the resolving phases. However, little is known about how inflammation reappears in a late phase sterile wound environment, what is the inciting stimulus, and what are the precise signals that can turn it off or resolve the inflammatory response. Additionally, inflammation seen in fibrotic wounds may exert a dominant effect, including collateral damage inflicted on otherwise healthy cells and tissue, which in turn causes continued remodeling and excessive scarring $[99,100]$.

Although scarring may be defined as an excessive deposition of matrix components that results in destruction of normal tissue architecture and a compromise in tissue function, it is also a failure to 'stop' healing or transition to a mature matrix [98]. The development of excessive scarring appears to initially follow a similar pathway to that of normal wound 
healing; however, in most cases, there is a chronic progression of the disease without resolution. Does this process develop at the onset of the initial insult or is it set into motion at some point along the way? It has been suggested that it generally develops after an initial insult which leads to cellular injury in which scarring is characterized as reparative. In contrast, fibrosis may develop as a result of excessive matrix deposition surrounding normal parenchyma, wherein excessive matrix deposition is not triggered by tissue injury but rather by a direct stimulation from local factors [98]. The increase in matrix surrounding the cellular compartment compromises function, which may further trigger the onset of the reparative form of scarring in a feed-forward loop. This suggests that there are stop signals that synchronize the termination of the regenerative phase. Therefore, excessive scarring appears to be determined by: (1) excessive synthesis of collagen and other ECM components; (2) dysfunction in the resolution and down regulation of the degradative enzymes involved in removing the scar tissue; and (3) loss or downregulation of key stop signals.

\section{Final synthesis}

Fibrosis that characterizes scarring likely results from the failure of the wound to properly transition from the regenerative phase to the resolving phase. Thus, the wound maintains a pro-stimulatory matrix with fibronectin and tenascin-C featured prominently and relatively devoid of the suppressive SLRPs. In conjunction with such an immature matrix, matrix proteases are elevated, which degrade the newly deposited collagen and generating chemotactic fragments that recruit inflammatory and stromal cells, that are activated by the matrikines and soluble factors in such a bio-active matrix to produce more matrix (Fig. 3). Further aggravating the scar is the rigidity of the ECM, which in itself leads to activation of macrophages and the transition of stromal cells to myofibroblasts, that, in turn, contract and stiffen the matrix. The increase in cellularity and matrix continues until the ensuing death of the excess cells limits the matrix turnover and thereby heralds the end stage of fibrosis which is characterized by a stiff, 'sclerotic' matrix.

This scenario posits that fibrosis and scarring results from failure to stop rather than a specific continuing insult. The healing process normally gets both turned on and then turned off. In the absence of such off signals, there is an increase in cell proliferation, matrix and cell death resulting in a non-resolved, fibrotic wound. The signals also dictate the cells that generate mechanical tension and affect the stiffness of the matrix. Still, a number of issues are unclear. While there is a definite ethnic and individual predilection to scarring, wounds in such situations do resolve over time. Thus, the extent of genetic predisposition needs to be determined as to whether it impacts excessive scarring. In addition, the cause of the failure to heal in these situations is unknown, unlike the experimental situation of the CXCR3abrogated mice. These are just a few of the key questions that need experimentation to define the triggering events for scarring. Such exposition would allow for rational therapies to prevent scarring.

\section{Acknowledgments}

These studies were supported by grants from the National Institute of General Medical Science of the National Institutes of Health (USA) (GM063569). Services in kind were provided by the Pittsburgh VA Medical Center.

\section{References}

1. Singer AJ, Clark RA. Cutaneous wound healing. N Engl J Med. 1999; 341:738-746. [PubMed: 10471461]

2. Harty M, Neff AW, King MW, Mescher AL. Regeneration or scarring: an immunologic perspective. Dev Dyn. 2003; 226:268-279. [PubMed: 12557205] 
3. Hynes RO. The extracellular matrix: not just pretty fibrils. Science. 2009; 326:1216-1219. [PubMed: 19965464]

4. Gurtner GC, Werner S, Barrandon Y, Longaker MT. Wound repair and regeneration. Nature. 2008; 45:314-321. [PubMed: 18480812]

5. Trent JT, Kirsner RS. Wounds and malignancy. Adv Skin Wound Care. 2006; 16:31-34. [PubMed: 12582304]

6. Blanpain C, Lowry WE, Geoghegan A, Polak L, Fuchs E. Self-renewal, multipotency, and the existence of two cell populations within an epithelial stem cell niche. Cell. 2004; 118:635-648. [PubMed: 15339667]

7. Nelson CM, Bissell MJ. Of extracellular matrix, scaffolds, and signaling: tissue architecture regulates development, homeostasis, and cancer. Annu Rev Cell Dev Biol. 2006; 22:287-309. [PubMed: 16824016]

8. Liu Y, Min D, Bolton T, et al. Increased matrix metalloproteinase-9 predicts poor wound healing in diabetic foot ulcers. Diabetes Care. 2009; 32:117-119. [PubMed: 18835949]

9. James GA, Swogger E, Wolcott R, et al. Biofilms in chronic wounds. Wound Repair Regen. 2008; 16:37-44. [PubMed: 18086294]

10. Wynn T. Cellular and molecular mechanisms of fibrosis. J Pathol. 2008; 214:199-210. [PubMed: 18161745]

11. Werner S, Krieg T, Smola H. Keratinocyte-fibroblast interactions in wound healing. J Invest Dermatol. 2007; 127:998-1008. [PubMed: 17435785]

12. Martin P. Wound healing_aiming for perfect skin regeneration. Science. 1997; 276:75-81. [PubMed: 9082989]

13. Adzick NS, Harrison MR, Glick PL, Beckstead JH, Villa RL, Scheuenstuhl H, Goodson WH. Comparison of fetal, newborn, and adult wound healing by histologic, enzyme-histochemical, and hydroxyproline determinations. J Pediatr Surg. 1985; 20:315-319. [PubMed: 4045654]

14. Yamaguchi Y, Yoshikawa K. Cutaneous wound healing: an update. J Dermatol. 2001; 28:521-534. [PubMed: 11732719]

15. Schultz, G. Dynamic reciprocity—how cells and extracellular matrix communicate to heal wounds. Third Congress of the World Union of Wound Healing Societies; Canada. 2008.

16. Eckes B, Nischt R, Krieg T. Cell-matrix interactions in dermal repair and scarring. Fibrogenesis Tissue Repair. 2010; 3:4. [PubMed: 20222960]

17. Widgerow AD, Chait LAC, Stals R, Stals P, Candy G. Multimodality scar management program. Aesthetic Plast Surg. 2009; 33:533. [PubMed: 19048338]

18. Siebert JW, Burd AR, McCarthy JG, Weinzweig J, Ehrlich HP. Fetal wound healing: a biochemical study of scarless healing. Plast Reconstr Surg. 1990; 85:495-504. [PubMed: 2315389]

19. Woolley K, Martin P. Conserved mechanisms of repair: from damaged single cells to wounds in multicellular tissues. Bioessays. 2000; 22:911-919. [PubMed: 10984717]

20. Coolen NA, Schouten KC, Middelkoop E, et al. Comparison between human fetal and adult skin. Arch Dermatol Res. 2010; 302:47-55. [PubMed: 19701759]

21. Lorenz HP, Longaker MT, Perkocha LA, et al. Scarless wound repair: a human fetal skin model. Development. 1992; 114:253-259. [PubMed: 1576963]

22. Tran KT, Lamb P, Deng JS. Matrikines and matricryptins: implications for cutaneous cancers and skin repair. J Dermatol Sci. 2004; 40:11-20. [PubMed: 15993569]

23. Tran KT, Griffith L, Wells A. Extracellular matrix signaling through growth factor receptors during wound healing. Wound Repair Regen. 2004; 12:262-268. [PubMed: 15225204]

24. Giannelli G, Falk-Marzillier J, Schiraldi O, Stetler-Stevenson WG, Quaranta V. Induction of cell migration by matrix metalloprotease-2 cleavage of laminin-5. Science. 1997; 277:225-228. [PubMed: 9211848]

25. Aarabi S, Longaker MT, Gurtner GC. Hypertrophic scar formation following burns and trauma: new approaches to treatment. PLoS Med. 2007; 4:e234. [PubMed: 17803351]

26. Niessen FB, Spauwen PH, Schalkwijk J, Kon M. On the nature of hypertrophic scars and keloids: a review. Plast Reconstr Surg. 2008; 104:1435-1458. [PubMed: 10513931] 
27. Martin P, Parkhurst SM. Parallels between tissue repair and embryo morphogenesis. Development. 2004; 131:3021-3034. [PubMed: 15197160]

28. Martin P, Lewis J. Actin cables and epidermal movement in embryonic wound healing. Nature. 1992; 360:179-183. [PubMed: 1436096]

29. Colwell AS, Longaker MT, Lorenz H. Fetal wound healing. Front Biosci. 2003; 8:s1240-s1248. [PubMed: 12957846]

30. Chen W, Fu X, Ge S, Sun T, Zhou G, Jiang D, Sheng Z. Ontogeny of expression of transforming growth factor-beta and its receptors and their possible relationship with scarless healing in human fetal skin. Wound Repair Regen. 2005; 13:68-75. [PubMed: 15659038]

31. Ferguson MW, O'Kane S. Scar-free healing: from embryonic mechanisms to adult therapeutic intervention. Philos Trans R Soc Lond B. 2004; 359:839-850. [PubMed: 15293811]

32. Armour A, Scott PG, Tredget EE. Cellular and molecular pathology of HTS: basis for treatment. Wound Repair Regen. 2007; 15:S6-S17. [PubMed: 17727469]

33. Mehrad B, Keane MP, Gomperts BN, Strieter RM. Circulating progenitor cells in chronic lung disease. Expert Rev Respir Med. 2007; 1:157-165. [PubMed: 20477275]

34. Zeisberg EM, Tarnavski O, Zeisberg M, et al. Endothelial-to-mesenchymal transition contributes to cardiac fibrosis. Nat Med. 2007; 13:952-961. [PubMed: 17660828]

35. Zeisberg M, Yang C, Martino M, Duncan MB, Rieder F, Tanjore H, Kalluri R. Fibroblasts derive from hepatocytes in liver fibrosis via epithelial to mesenchymal transition. J Biol Chem. 2007; 282:23337-23347. [PubMed: 17562716]

36. National Heart Blood Institute Lung Mortality Morbidity. Chart book on cardiovascular, lung, and blood diseases. US Department of Health and Human Services; Bethesda: 2002.

37. Babu M, Wells A. Dermal-epidermal communication in wound healing. Wounds. 2002; 13:183189. 2001.

38. Neilson EG. Mechanisms of disease fibroblasts-a new look at an old problem. Nat Clin Pract Nephrol. 2006; 2:101-108. [PubMed: 16932401]

39. Tomasek JJ, Gabbiani G, Hinz B, Chaponnier C, Brown RA. Myofibroblasts and mechanoregulation of connective tissue remodelling. Nat Rev Mol Cell Biol. 2002; 3:349-363. [PubMed: 11988769]

40. Eckes B, Krieg T. Regulation of connective tissue homeostasis in the skin by mechanical forces. Clin Exp Rheumatol. 2004; 22:S73-S76. [PubMed: 15344602]

41. Rivera J, Lozano ML, Navarro-Nunez L, Vicente V. Platelet receptors and signaling in the dynamics of thrombus formation. Haematologica. 2009; 94:700-711. [PubMed: 19286885]

42. Nieswandt B, Varga-Szabo D, Elvers M. Integrins in platelet activation. J Thromb Haemost. 2009; 7:206-209. [PubMed: 19630801]

43. Theilgaard-Monch K, Knudsen S, Follin P, Borregaard N. The transcriptional activation program of human neutrophils in skin lesions supports their important role in wound healing. J Immunol. 2004; 172:7684-7693. [PubMed: 15187151]

44. Werner S, Grose R. Regulation of wound healing by growth factors and cytokines. Physiol Rev. 2003; 83:835-870. [PubMed: 12843410]

45. Clark RA. Biology of dermal wound repair. Dermatol Clin. 1993; 11:647-666. [PubMed: 8222349]

46. Greiling D, Clark RA. Fibronectin provides a conduit for fibroblast transmigration from collagenous stroma into fibrin clot provisional matrix. J Cell Sci. 1997; 110:861-870. [PubMed: 9133673]

47. McDonald JA, Kelley DG, Broekelmann TJ. Role of fibronectin in collagen deposition: fab' to the gelatin-binding domain of fibronectin inhibits both fibronectin and collagen organization in fibroblast extracellular matrix. J Cell Biol. 1982; 92:485-495. [PubMed: 7061591]

48. Lucas T, Waisman A, Ranjan R, Roes J, Krieg T, Müller W, Roers A, Eming SA. Differential roles of macrophages in diverse phases of skin repair. J Immunol. 2010; 184:3964-3977. [PubMed: 20176743]

49. Roberts AB, Heine UI, Flanders KC, Sporn MB. Transforming growth factor-beta. Major role in regulation of extracellular matrix. Ann NY Acad Sci. 1990; 580:225-232. [PubMed: 2186691] 
50. Raab G, Klagsbrun M. Heparin-binding EGF-like growth factor. Biochim Biophys Acta. 1997; 1333:F179-F199. [PubMed: 9426203]

51. Marikovsky M, Breuing K, Liu PY, et al. Appearance of heparin-binding EGF-like growth factor in wound fluid as a response to injury. Proc Natl Acad Sci USA. 1993; 90:3889-3893. [PubMed: 8483908]

52. Tonnesen MG, Feng X, Clark RA. Angiogenesis in wound healing. J Investig Dermatol Symp Proc. 2000; 5:40-46.

53. Herrick SE, Sloan P, McGurk M, Freak L, McCollum CN, Ferguson MW. Sequential changes in histologic pattern and extracellular matrix deposition during the healing of chronic venous ulcers. Am J Pathol. 1992; 141:1085-1095. [PubMed: 1279979]

54. Flaumenhaft R, Rifkin DB. Extracellular matrix regulation of growth factor and protease activity. Curr Opin Cell Biol. 1991; 3:817-823. [PubMed: 1931082]

55. Baneyx G, Baugh L, Vogel V. Fibronectin extension and unfolding within cell matrix fibrils controlled by cytoskeletal tension. Proc Natl Acad Sci USA. 2002; 99:5139-5143. [PubMed: 11959962]

56. Yan C, Grimm WA, Garner WL, et al. Epithelial to mesenchymal transition in human skin wound healing is induced by tumor necrosis factor-alpha through bone morphogenic protein-2. Am J Pathol. 2010; 176:2247-2258. [PubMed: 20304956]

57. Spaeth EL, Dembinski JL, Sasser AK, et al. Mesenchymal stem cell transition to tumor-associated fibroblasts contributes to fibrovascular network expansion and tumor progression. PLoS One. 2009; 4:e4992. [PubMed: 19352430]

58. Papetti M, Herman IM. Mechanisms of normal and tumor-derived angiogenesis. Am J Physiol Cell Physiol. 2002; 282:C947-C970. [PubMed: 11940508]

59. Iozzo RV, Schaefer L. Proteoglycans in health and disease: novel regulatory signaling mechanisms evoked by the small leucine-rich proteoglycans. FEBS J. 2010; 277:3864-3875. [PubMed: 20840584]

60. Hynes RO. The dynamic dialogue between cells and matrices: implications of fibronectin's elasticity. Proc Natl Acad Sci USA. 1999; 96:2588-2590. [PubMed: 10077553]

61. Clark RA. Fibronectin matrix deposition and fibronectin receptor expression in healing and normal skin. J Invest Dermatol. 1990; 94:128S-134S. [PubMed: 2161886]

62. Schultz GS, Wysocki A. Interactions between extracellular matrix and growth factors in wound healing. Wound Repair Regen. 2009; 17:153-162. [PubMed: 19320882]

63. Heino J. The collagen family members as cell adhesion proteins. Bioessays. 2007; 29:1001-1010. [PubMed: 17876790]

64. Romagnani P, Lasagni L, Annunziato F, Serio M, Romagnani S. CXC chemokines: the regulatory link between inflammation and angiogenesis. Trends Immunol. 2004; 25:201-209. [PubMed: 15039047]

65. Liu L, Callahan MK, Huang D, Ransohoff RM. Chemokine receptor CXCR3: an unexpected enigma. Curr Top Dev Biol. 2005; 68:149-181. [PubMed: 16124999]

66. Clark RA. Regulation of fibroplasia in cutaneous wound repair. Am J Med Sci. 1993; 306:42-48. [PubMed: 8328509]

67. Juhasz I, Murphy GF, Yan HC, Herlyn M, Albelda S. Regulation of extracellular matrix proteins and integrin cell substratum adhesion receptors on epithelium during cutaneous human wound healing in vivo. Am J Pathol. 1993; 143:1458-1469. [PubMed: 7694470]

68. Werner S, Krieg T, Smola H. Keratinocyte-fibroblast interactions in wound healing. J Invest Dermatol. 2001; 127:998-1008. [PubMed: 17435785]

69. Vuorio E, de Crombrugghe B. The family of collagen genes. Annu Rev Biochem. 1990; 59:837872. [PubMed: 2197991]

70. Jaffe AT, Heymann WR, Lawrence N. Epidermal maturation arrest. Dermatol Surg. 1995; 25:900903. [PubMed: 10594606]

71. Gipson IK, Spurr-Michaud SJ, Tisdale AS. Hemidesmosomes and anchoring fibril collagen appear synchronously during development and wound healing. Dev Biol. 1988; 126:253-262. [PubMed: 3350210] 
72. Shiraha H, Gupta K, Drabik KA, Wells A. Aging fibro-blasts present reduced epidermal growth factor (EGF) responsiveness due to preferential loss of EGF receptors. J Biol Chem. 2000; 275:19343-19351. [PubMed: 10764734]

73. Chen P, Gupta K, Wells A. Cell movement elicited by epidermal growth factor receptor requires kinase and auto-phosphorylation but is separable from mitogenesis. J Cell Biol. 1994; 124:547555. [PubMed: 8106552]

74. Shiraha H, Glading A, Wells A. Activation of M-calpain (calpain II) by epidermal growth factor is limited by PKA phosphorylation of M-calpain. Mol Cell Biol. 2002; 22:2716-2727. [PubMed: 11909964]

75. Muro AF, Chauhan AK, Gajovic S, Iaconcig A, Porro F, Stanta G, Baralle FE. Regulated splicing of the fibronectin EDA exon is essential for proper skin wound healing and normal lifespan. J Cell Biol. 2003; 162:149-160. [PubMed: 12847088]

76. Wierzbicka-Patynowski I, Schwarzbauer JE. The ins and outs of fibronectin matrix assembly. J Cell Sci. 2003; 116:3269-3276. [PubMed: 12857786]

77. Velling T, Risteli J, Wennerberg K, Mosher DF, Johansson S. Polymerization of type I and III collagens is dependent on fibronectin and enhanced by integrins alpha 11 beta 1 and alpha 2 beta 1 . J Biol Chem. 2002; 277:37377-37381. [PubMed: 12145303]

78. Iyer AK, Tran KT, Borysenko CW, Cascio M, Camacho CJ, Blair HC, Bahar I, Wells A. Tenascin cytotactin epidermal growth factor-like repeat binds epidermal growth factor receptor with low affinity. J Cell Physiol. 2007; 211:748-758. [PubMed: 17311283]

79. Iyer AK, Tran KT, Griffith L, Wells A. Cell surface restriction of EGFR by a tenascin cytotactinencoded EGF-like repeat is preferential for motility-related signaling. J Cell Physiol. 2008; 214:504-512. [PubMed: 17708541]

80. Swindle CS, Tran KT, Johnson TD, Banerjee P, Mayes AM, Griffith L, Wells A. Epidermal growth factor (EGF)-like repeats of human tenascin-C as ligands for EGF receptor. J Cell Biol. 2001; 154:459-468. [PubMed: 11470832]

81. Chiquet-Ehrismann R, Chiquet M. Tenascins: regulation and putative functions during pathological stress. J Pathol. 2003; 200:488-499. [PubMed: 12845616]

82. Trebaul A, Chan EK, Midwood KS. Regulation of fibroblast migration by tenascin-C. Biochem Soc Trans. 2007; 35:695-697. [PubMed: 17635125]

83. Mann K, Deutzmann R, Aumailley M, Timpl R, Raimondi L, Yamada Y, Pan TC, Conway D, Chu ML. Amino acid sequence of mouse nidogen, a multidomain basement membrane protein with binding activity for laminin, collagen IV and cells. EMBO. 1989; 8:65-72.

84. Chakravarti S, Tam MF, Cheung AE. The basement membrane glycoprotein entactin promotes cell attachment and binds calcium. J Biol Chem. 1990; 265:10597-10603. [PubMed: 2191952]

85. Merline R, Schaefer RM, Schaefer L. The matricellular functions of small leucine-rich proteoglycans (SLRPs). J Cell Commun Signal. 2009; 3:323-335. [PubMed: 19809894]

86. Reed CC, Iozzo RV. The role of decorin in collagen fibrillogenesis and skin homeostasis. Glycoconj J. 2002; 19:249-255. [PubMed: 12975602]

87. Zhang Z, Li XJ, Liu Y, Zhang X, Li YY, Xu WS. Recombinant human decorin inhibits cell proliferation and downregulates TGF-beta1 production in hypertrophic scar fibroblasts. Burns. 2007; 33:634-641. [PubMed: 17374457]

88. Krishna P, Regner M, Palko J, Liu F, Abramowitch S, Jiang J, Wells A. The effects of decorin and HGF-primed vocal fold fibroblasts in vitro and ex vivo in a porcine model of vocal fold scarring. Laryngoscope. 2010; 120:2247-2257. [PubMed: 20830759]

89. Flier J, Boorsma DM, van Beek PJ, Nieboer C, Stoof TJ, Willemze R, Tensen CP. Differential expression of CXCR3 targeting chemokines CXCL10, CXCL9, and CXCL11 in different types of skin inflammation. J Pathol. 2001; 194:398-405. [PubMed: 11523046]

90. Tensen CP, Flier J, van der Raaij-Helmer EM, et al. Human IP-9. A keratinocyte-derived high affinity CXC-chemokine ligand for the IP-10/Mig receptor (CXCR3). J Invest Dermatol. 1999; 112:716-722. [PubMed: 10233762]

91. Satish L, Yager D, Wells A. ELR-negative CXC chemokine IP-9 as a mediator of epidermaldermal communication during wound repair. J Invest Dermatol. 2003; 120:1110-1117. [PubMed: 12787142] 
92. Yates CC, Whaley D, Kulasekeran P, Hancock WW, Lu B, Bodnar R, Newsome J, Hebda PA, Wells A. Delayed and deficient dermal maturation in mice lacking the CXCR3 ELR-negative CXC chemokine receptor. Am J Pathol. 2007; 171:484-495. [PubMed: 17600132]

93. Yates CC, Whaley D, Yen A, Kulesekaran P, Hebda PA, Wells A. ELR-negative CXC chemokine CXCL11(IP-9/I-TAC) facilitates dermal and epidermal maturation during wound repair. Am J Pathol. 2008; 173:643-652. [PubMed: 18669615]

94. Bodnar R, Yates C, Wells A. IP-10 blocks VEGF-induced endothelial cell motility and tube formation via inhibition of calpain. Circ Res. 2006; 98:617-625. [PubMed: 16484616]

95. Bodnar RJ, Yates CC, Du X, Wells A. ELR-negative chemokine IP-10/CXCL10 induces dissociation of newly-formed vessels secondary to calpain cleavage of beta3 integrin. J Cell Sci. 2009; 122:2064-2077. [PubMed: 19470579]

96. Shiraha H, Glading A, Chou J, Jia Z, Wells A. Activation of m-calpain (calpain II) by epidermal growth factor is limited by PKA phosphorylation of m-calpain. Mol Cell Biol. 2002; 22:27162720. [PubMed: 11909964]

97. Yates CC, Whaley D, Hooda S, Hebda PA, Bodnar RJ, Wells A. Delayed re-epithelialization and basement membrane regeneration after wounding in mice lacking CXCR3. Wound Repair Regen. 2009; 17:34-41. [PubMed: 19152649]

98. Yates CC, Krishna P, Whaley D, Bodnar R, Turner T, Wells A. Lack of CXC chemokine receptor 3 signaling leads to hypertrophic and hypercellular scarring. Am J Pathol. 2010; 176:1743-1755. [PubMed: 20203286]

99. Stramer BM, Mori R, Martin P. The inflammation-fibrosis link? A Jekyll and Hyde role for blood cells during wound repair. J Invest Dermatol. 2007; 127:1009-1017. [PubMed: 17435786]

100. Raghow R. The role of extracellular matrix in postinflammatory wound healing and fibrosis. FASEB J. 1994; 8:823-831. [PubMed: 8070631] 


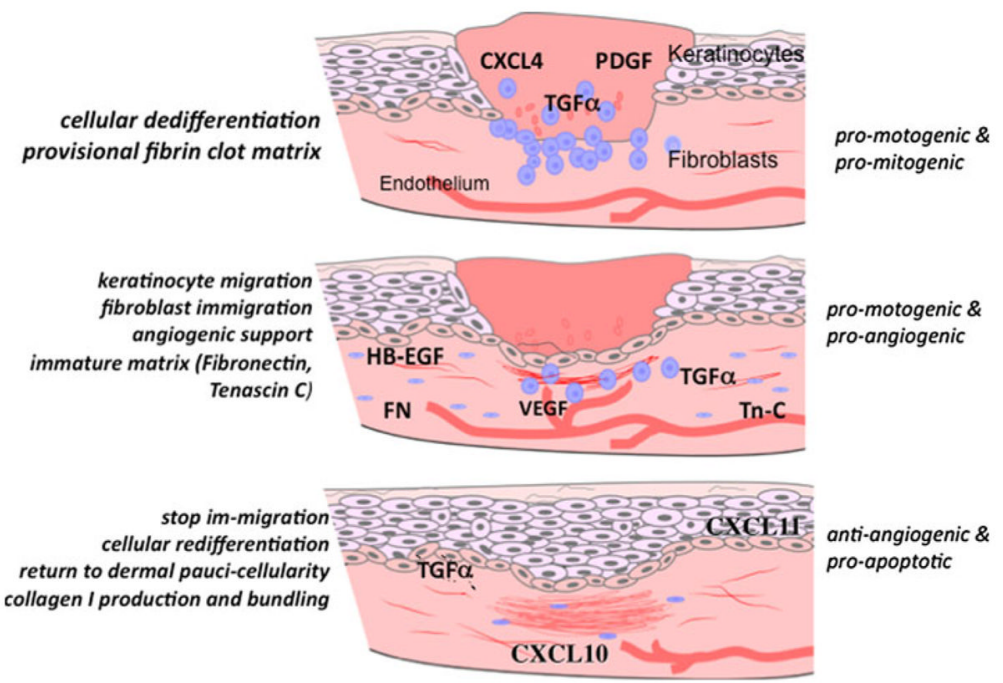

Fig. 1.

Healing by secondary intention involves the closure of a large open defect, and in skin wound healing proceeds through stages that effect repair approaching the original tissue via a wave of signaling factors that orchestrate the cells to generate a paucicellular barrier to the external hostile environment. It is critical that early in the process pro-stimulatory signals recruit cells to replace the lost tissue. However, late in the tissue formation and early in the tissue remodeling phase, other signals are needed to shut off this exuberant response.

Growth factors and chemokines function during these phases as "stop" signals. CXCL11/ IP-9 is made by redifferentiated keratinocytes that have covered their denuded provisional matrix and CXCL10/IP-10 is produced by nascent blood vessels. These chemokines maintain the de-differentiated state of migrating keratinocytes while causing the dermal fibroblasts to 'differentiate' to produce mature matrix. (Note, the initial stage of hemostasis is not shown here) 


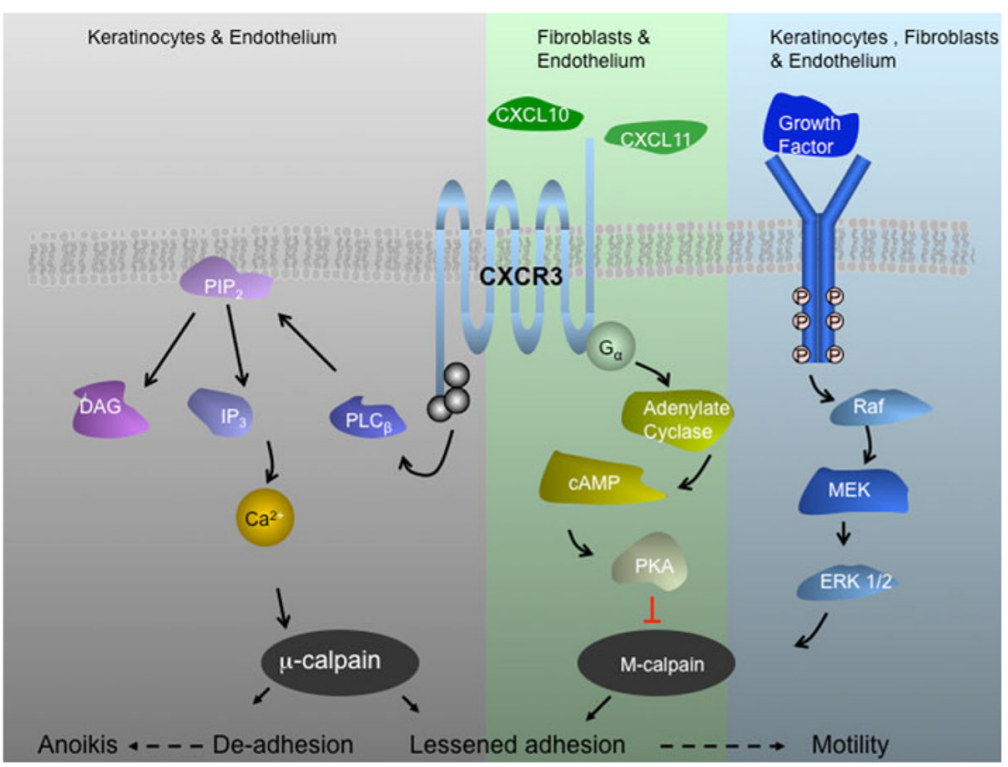

Fig. 2.

CXCR3 signaling axis during wound repair. CXCR3 receptor is a seven transmembrane $\mathrm{G}$ protein coupled receptor. This signaling system is extant in human and rodent with the receptor being ubiquitous but the ligands being regulated temporally and spatially. CXCR3 receptor is expressed on keratinocytes, fibroblast, and endothelial cells. CXCL10/IP-10 appears in the dermis and is produced by endothelial cells of the neovasculature and CXCL11/IP-9 is expressed from redifferentiating keratinocytes behind the leading edge of the wound. These secreted peptide factors, both CXC chemokines that lack the canonical Nterminal sequence ELR (glutamic acid-leucine-arginine), bind in common to the ubiquitous CXCR3 chemokine receptor. Signaling through CXCR3 blocks growth factor-induced motility of fibroblasts and endothelial cells by suppressing $m$-calpain activation. In contrast, these chemokines do not block the motility of dedifferentiated keratinocytes but rather increase their motility via lessened adhesiveness that shifts the cell into the most permissive adhesion/contractility state and thus promotes motility and in turn more rapid reepithelialization. For endothelial cells, in which the $\beta 3$ integrin predominates, CXCR3 activation of calpain $1 / \mu$-calpain leads to detachment and anoikis 


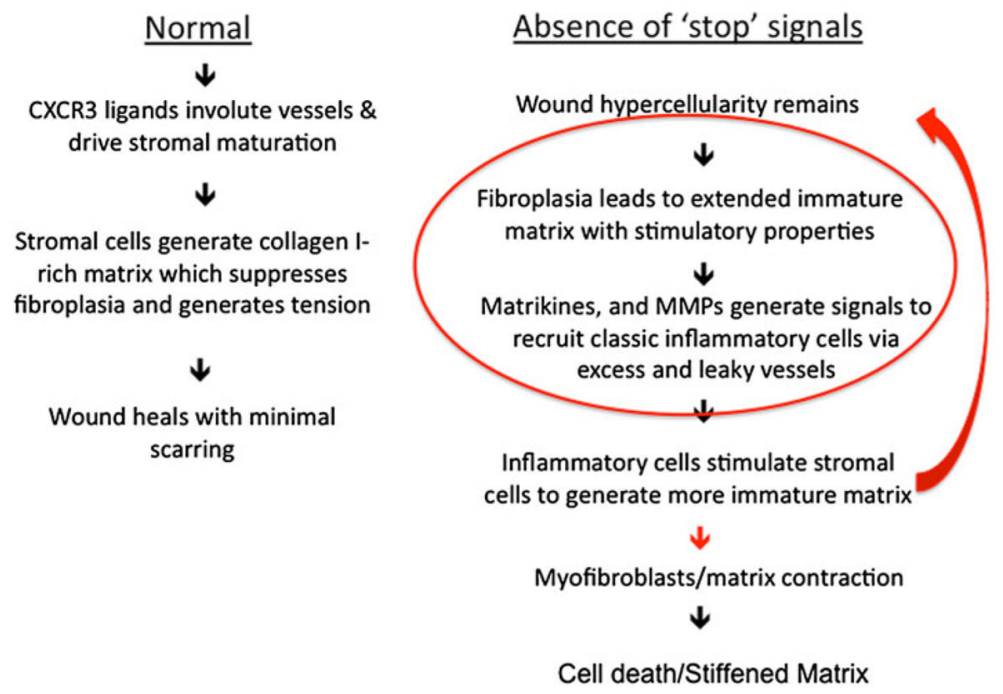

Fig. 3.

Process flow representation of wound healing. Usually the process is unidirectional resulting in minimal scarring (Normal). However, in the Absence of 'stop' signals (e.g., deficit of CXCR3 signaling) the fibroplasia results in an immature matrix which in turns recruits more inflammatory cells that stimulate the stromal cells to produce more regenerative matrix. This results in a feed-forward loop in which the regenerative matrix is central to driving further scarring. This process slows down when the myofibroblasts contract the matrix, with the fibrosis leading to the death of the excess cells and leaving a fibrotic, sclerotic dermis 
Table 1

\begin{tabular}{|c|c|c|c|c|}
\hline Select component & Phase(s) & Cellular expression & Key growth factor(s) & Function \\
\hline \multirow[t]{4}{*}{ Collagen I } & Hemostasis & \multirow{4}{*}{$\begin{array}{l}\text { Epithelial, endothelial, fibroblast, } \\
\text { smooth muscle, leukocytes, } \\
\text { platelets }\end{array}$} & bFGF & Tissue architecture \\
\hline & Inflammatory & & $\mathrm{TGF}-\beta$ & Tensile strength \\
\hline & Tissue formation & & PDGF & $\begin{array}{l}\text { Cell-matrix and matrix-matrix } \\
\text { interaction }\end{array}$ \\
\hline & Tissue remodeling & & EGF & ECM remodeling \\
\hline \multirow[t]{4}{*}{ Collagen III } & Hemostasis & \multirow{4}{*}{$\begin{array}{l}\text { Epithelial, endothelial, fibroblast, } \\
\text { leukocytes, platelets }\end{array}$} & EGF & Tissue architecture \\
\hline & Inflammatory & & TGF- $\beta$ & Matrix-matrix interaction \\
\hline & Tissue formation & & PDGF & Maturation and ECM remodeling \\
\hline & & & EGF & \\
\hline \multirow[t]{5}{*}{ Fibrinogen } & Hemostasis & \multirow{5}{*}{$\begin{array}{l}\text { Platelets, leukocytes, endothelial, } \\
\text { fibroblast }\end{array}$} & FGF-2 & Cell-cell interaction \\
\hline & Inflammatory & & VEGF & Cell-matrix \\
\hline & Tissue formation & & & Platelet-protein \\
\hline & & & & Cell proliferation \\
\hline & & & & Cell migration \\
\hline \multirow[t]{4}{*}{ Hyaluronan } & Tissue formation & \multirow{4}{*}{$\begin{array}{l}\text { Epithelial, fibroblast, smooth } \\
\text { muscle }\end{array}$} & TGF- $\beta 1$ & Cell-matrix interactions \\
\hline & Tissue remodeling & & EGF & Matrix-matrix interactions \\
\hline & & & Chemokines & Cell proliferation \\
\hline & & & & Cell migration \\
\hline \multirow[t]{4}{*}{ Fibronectin } & Hemostasis & \multirow{4}{*}{$\begin{array}{l}\text { Epithelial, endothelial, fibroblast, } \\
\text { leukocytes, platelets }\end{array}$} & PDGF & Tissue architecture \\
\hline & Inflammatory & & Chemokines & $\begin{array}{l}\text { Cell-matrix and matrix-matrix } \\
\text { interactions }\end{array}$ \\
\hline & Tissue formation & & & Cell proliferation and migration \\
\hline & Tissue remodeling & & & Opsonin \\
\hline \multirow[t]{3}{*}{ Tenascin $\mathrm{C}$} & Tissue formation & \multirow[t]{3}{*}{ Epithelial, fibroblast } & EGF-like repeats & Modulates cell-matrix \\
\hline & Tissue remodeling & & TGF- $\beta$ & Anti-adhesive \\
\hline & & & Chemokines & Anti-proliferative \\
\hline \multirow[t]{4}{*}{ Decorin } & Tissue formation & \multirow[t]{4}{*}{ Fibroblast } & EGF & Cell-matrix interactions \\
\hline & Tissue remodeling & & TGF- $\beta 1$ & Matrix-matrix interactions \\
\hline & & & Chemokines & $\begin{array}{l}\text { Bind and storage of growth } \\
\text { factors }\end{array}$ \\
\hline & & & & Cell proliferation \\
\hline \multirow[t]{3}{*}{ Entactin (or nidogen) } & Hemostasis & \multirow[t]{3}{*}{ Epithelial, fibroblast, neutrophil } & EGF & Basement membrane component \\
\hline & Inflammatory & & & Stabilizes basement membrane \\
\hline & Tissue formation & & & \\
\hline \multirow[t]{4}{*}{ Laminin } & Hemostasis & \multirow{4}{*}{$\begin{array}{l}\text { Epithelial, endothelial, fibroblast, } \\
\text { smooth muscle, platelets, } \\
\text { neutrophil, monocyte }\end{array}$} & EGF & Basement membrane component \\
\hline & Inflammatory & & Chemokines & Cell migration \\
\hline & Tissue formation & & & \\
\hline & Tissue remodeling & & & \\
\hline \multirow[t]{2}{*}{ Collagen IV } & Tissue formation & \multirow{2}{*}{$\begin{array}{l}\text { Epithelial, endothelial, fibroblast, } \\
\text { smooth muscle, platelets, } \\
\text { neutrophil, monocyte }\end{array}$} & EGF & Basement membrane component \\
\hline & Tissue remodeling & & Chemokines & Cell migration \\
\hline
\end{tabular}

